\title{
Individualized Treatment Plan for Gingival Enlargement: A Case Series
}

\section{Shivanand Aspalli*, Shirin A Mulla, Reetika Gaddale and Nagappa G}

Department of Periodontics and Oral Implantology, AME's Dental College and Hospital, Raichur, Karnataka, India

\begin{abstract}
Gingival enlargement is a frequent characteristic of gingival disease produced by excessive growth of gingival tissues or gingival inflammation or amalgamation of both with a distinctive spot in relevant works and has been linked to numerous factors like inflammation, medications, neoplasia, hormonal disturbances, and heredity. The following case series highlights four cases of gingival enlargement, one being Phenytoin-induced, second Amlodipine induced combined with inflammatory enlargement, third inflammatory gingival enlargement and the fourth being inflammatory gingival enlargement combined with mouth breathing. Management per case is different due to different etiologic factors. Hence, for all the cases first, a non-surgical approach was carried out and depending upon the enlargement resolution further surgical procedures with electrosurgery or gingivectomy were performed. Thus, a proper diagnosis with a thorough treatment plan can lead to effective case management.
\end{abstract}

Keywords: Calcium channel blocker; Gingival enlargement; Gingival overgrowth; Inflammatory gingival enlargement; Phenytoin

\section{Introduction}

Excessive growth of gingival tissues in gingival disease is a frequent entity. The modern word for this disorder is a gingival enlargement or gingival overgrowth. Hyperplasia is a histologic term which should be distinguished from hypertrophy.

Gingival enlargement is related to multiple factors like inflammatory, systemic, hormonal, genetic, on the usage of drugs and other idiopathic factors [1-3]. At present, around 20 or more drugs are linked to gingival enlargement [4]. These drugs that produce gingival enlargement as a side effect are classified into 3 divisions:

\section{Anticonvulsants}

2. Calcium channel blockers-Amlodipine is less frequent

3. Immunosuppressants $[5,6]$

Gingival enlargement is frequently seen in day to day practice and its proper therapy includes the analysis of the cause of the enlargement. The usual form of enlargement is inflammatory enlargement which is seeded by the plaque adjacent to the gingiva. When the gingival condition is fibrotic, it might not subside completely, which results in the existence of a periodontal pocket that impedes oral hygiene maintenance. In such a state, a thorough and more complete longlasting treatment has to be formulated which involves the gingival and periodontal tissues. Further, a surgical approach may be deemed necessary to excise enlarged tissue and improve the access for patient's oral hygiene [7].

In the present case series, highlights of four gingival enlargements are described, one being a case of Phenytoin-induced gingival enlargement, second combined enlargement (Amlodipine and inflammatory), third inflammatory gingival.

Text enlargement and the fourth inflammatory gingival enlargement combined with mouth breathing.

\section{Case Series}

\section{Case 1}

The 22-year aged woman presented to the Department of Periodontics, with a history of swollen and bleeding gums, fetid odor and pus discharge since a year (Figure 1).
Her medical history revealed epilepsy since the age of 3, controlled with medication (Phenytoin) for the last 19 years. Gingival tissues were pale pink, enlarged, firm, and fibrotic. Generalized bleeding on probing was present. An orthopantomogram of the patient revealed considerable bone loss in the lower posterior regions. Complete hemogram results were under normal limits.

A diagnosis of generalized drug-induced gingival enlargement superimposed with chronic periodontitis was made. With the consent of the patient and her physician, complete scaling and root planing was performed, along with a prescription of a $0.2 \%$ chlorhexidine mouthwash. After 1 week, the gingival condition improved and the case was subjected to routine oral hygiene with a soft, gentle toothbrush and warm saline gargles.

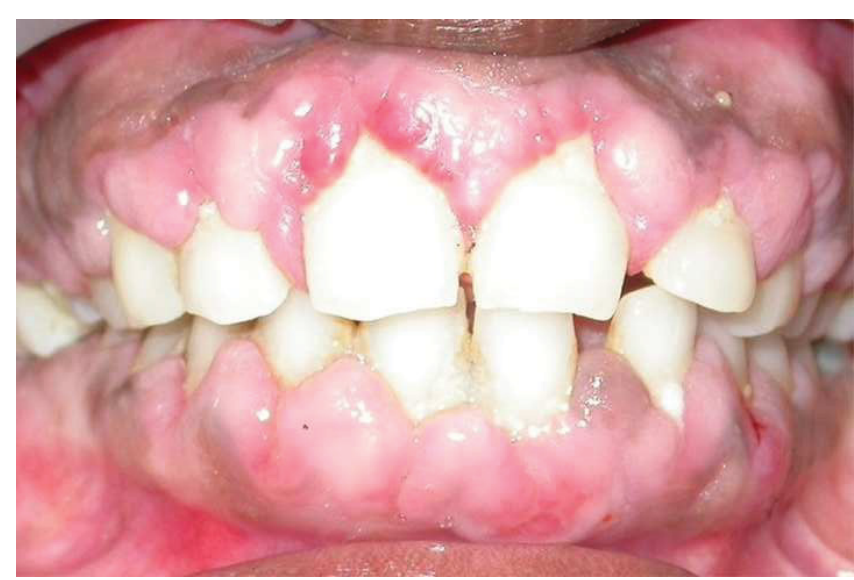

Figure 1: Pre-operative view of case 1

*Corresponding author: Shivanand Aspalli, Department of Periodontics and Ora Implantology, AME's Dental College and Hospital, Raichur, Karnataka, India, Tel: +91 9886000809; E-mail: rameperio@gmail.co

Received February 26, 2019; Accepted March 07, 2019; Published March 14 2019

Citation: Aspalli S, Mulla SA, Gaddale R, Nagappa G (2019) Individualized Treatment Plan for Gingival Enlargement: A Case Series. Dentistry 9: 537. doi:10.4172/2161-1122.1000537

Copyright: $\odot 2019$ Aspalli S, et al. This is an open-access article distributed under the terms of the Creative Commons Attribution License, which permits unrestricted use, distribution, and reproduction in any medium, provided the original author and source are credited. 
Citation: Aspalli S, Mulla SA, Gaddale R, Nagappa G (2019) Individualized Treatment Plan for Gingival Enlargement: A Case Series. Dentistry 9: 537. doi:10.4172/2161-1122.1000537

With the patient's and physician's consent, Phenytoin was substituted with sodium valproate $(500 \mathrm{mg}$ TID after titration of the dose). The patient was recalled for supportive periodontal therapy at an interval of 1, 3 and 6 months respectively (Figure 2).

\section{Case 2}

A 60-year aged woman presented to the department of Periodontics with inflamed, swollen and bleeding gums (Figure 3). On general examination, the patient was medium build; she was suffering from hypertension from 2 years and was under Amlodipine therapy. E.C.G and blood investigations were reported to be in the required range. Oral examination was done, revealing the absence of lower first molar on the left side and on right side both premolars were carious. A generalized gingival enlargement was evident.

Probing depth recorded was 3-4 $\mathrm{mm}$ with hindrance due to calculus. Radiographic examination with Orthopantomogram revealed a generalized moderate horizontal bone loss (Figure 4).

Prior to local management, the patient was thoroughly assessed by a physician and complete blood picture was normal. Full mouth supra and subgingival scaling were carried out (Figure 5). Restoration of carious teeth was carried out. The surgical procedure was performed with a modified Widman flap technique to reduce the pocket and excessive gingival tissues. The periodontal dressing was applied for 10

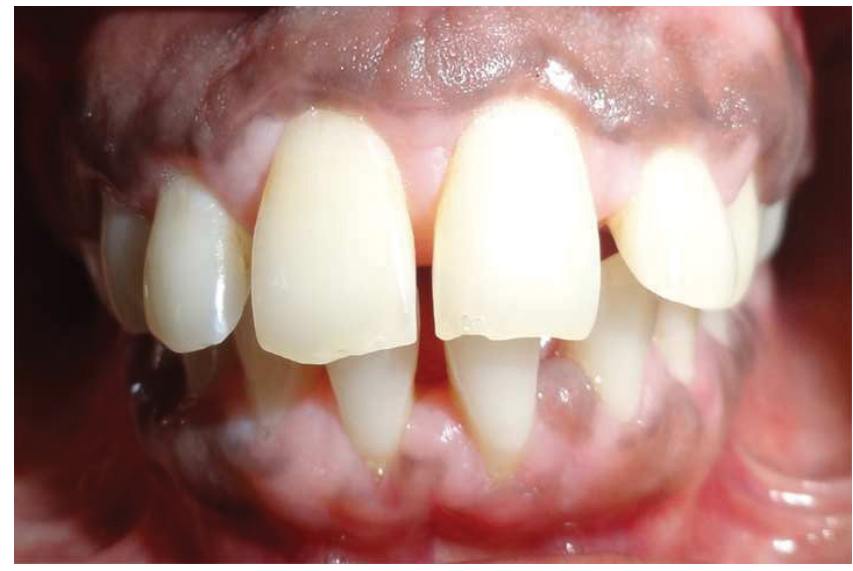

Figure 2: 6 months post-operative view of case 1.

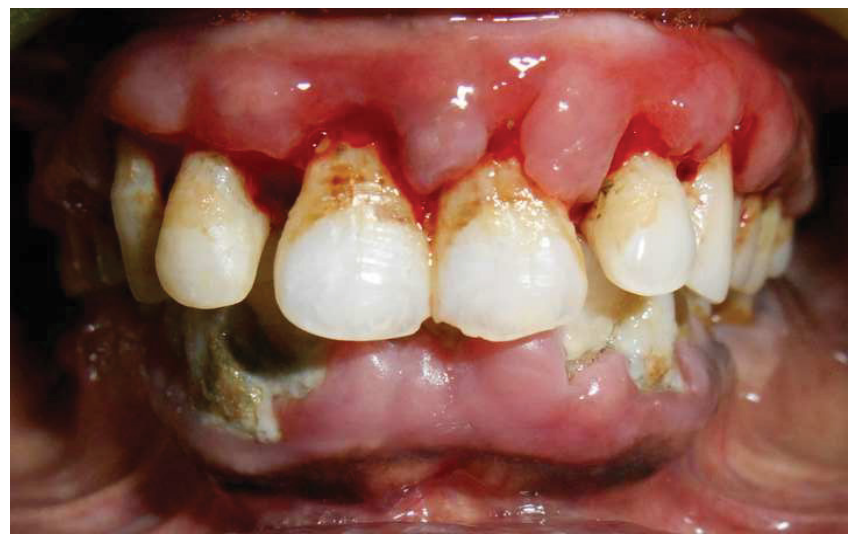

Figure 3: Pre-scaling view of case 2.

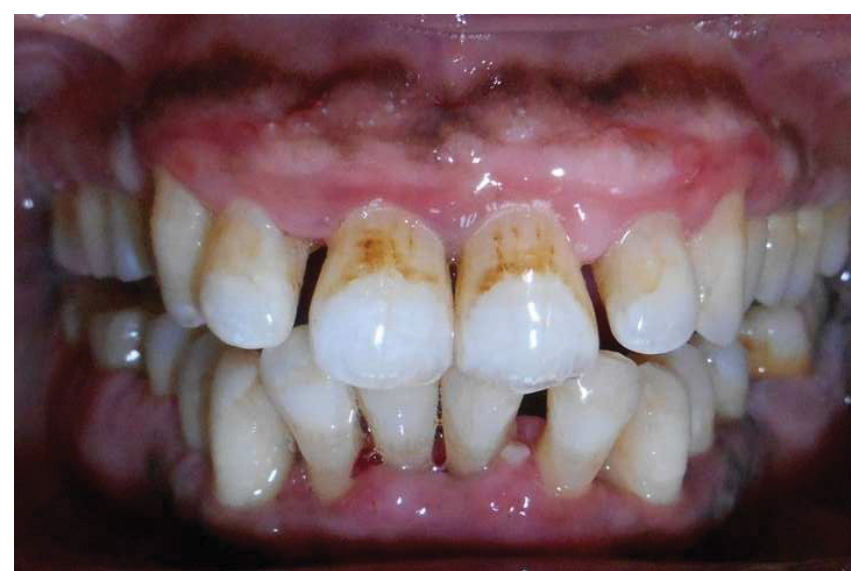

Figure 4: Post-scaling view of case 2

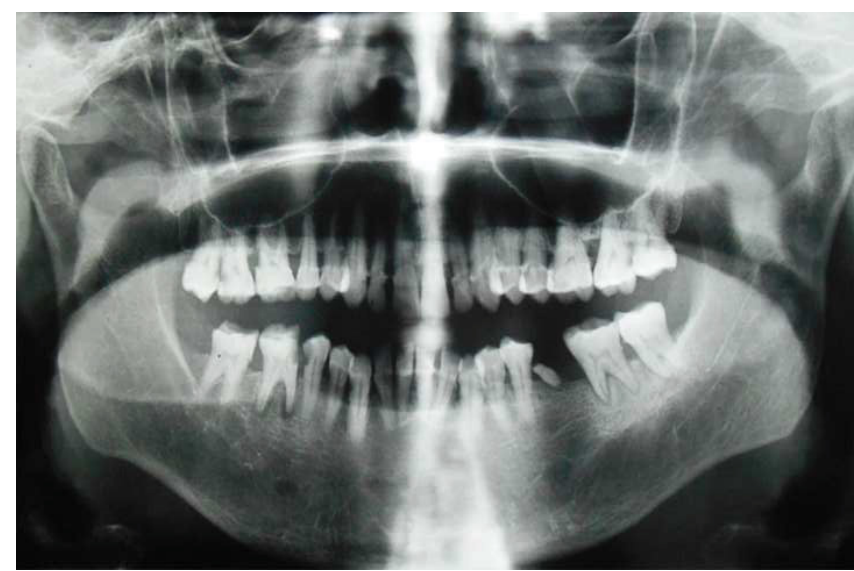

Figure 5: Radiographic examination with Orthopantomogram (OPG) of case 2

days. There were no postoperative complications and the healing was uneventful. The case was advised to maintain good oral care with put on regular follow-ups (Figure 6).

\section{Case 3}

The 23-aged woman presented to the outpatient department of Periodontics with a history of enlarged gums in both upper and lower front teeth, for 8 months. The patient also had a problem in chewing and was concerned for esthetic looks too (Figure 7). No previous history of any medications reported. When full mouth examination was carried out the severity of enlargement was grade 3 in both upper and lower front teeth with generalized bleeding from gums upon probing with probing depth more than $6 \mathrm{~mm}$ in front teeth. Oral prophylaxis was carried out followed by open flap debridement for the pre-existing pockets. Postoperatively there was the resolution of inflammation evident with healthy gingiva. The patient was monitored every 3 months thereafter and after 6 months orthodontic therapy was reinstituted to correct mal-alignment of teeth (Figure 8).

\section{Case 4}

A 25-year-old female patient visited the Department of Periodontics, 


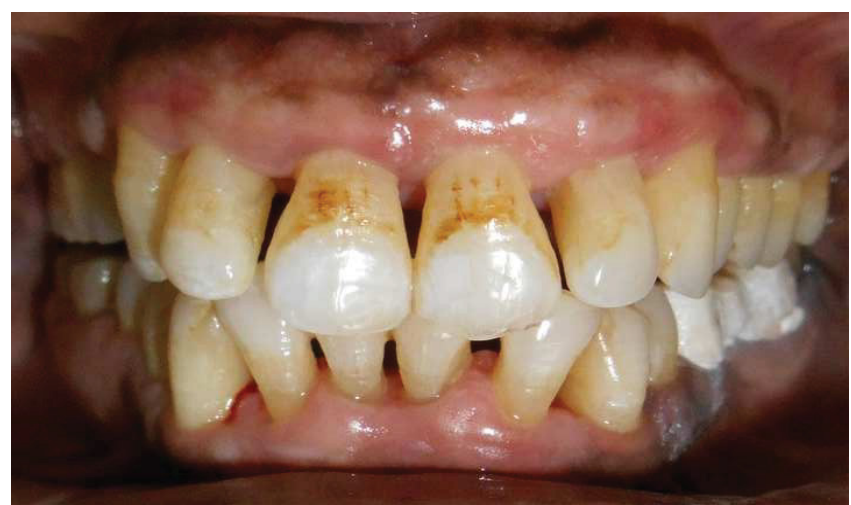

Figure 6: 6 months post-surgical view of case 2 .

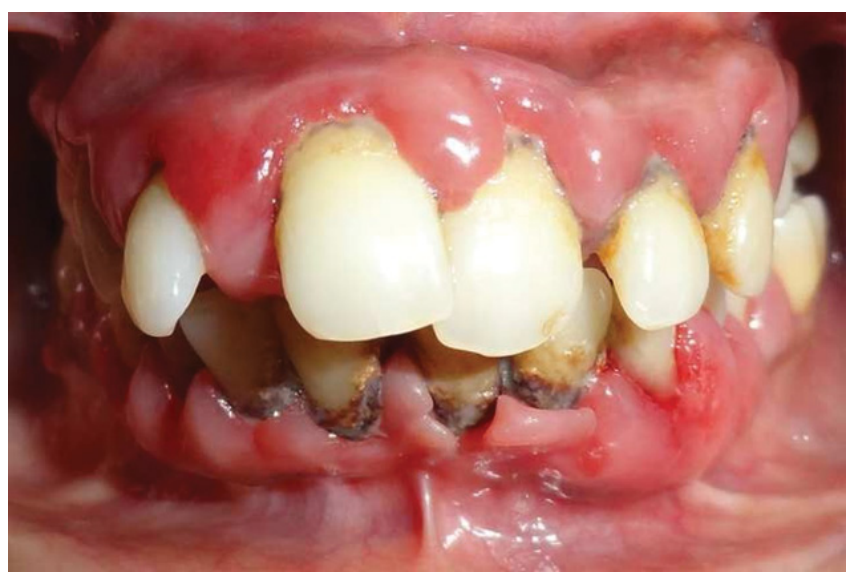

Figure 7: Pre-scaling view of case 3

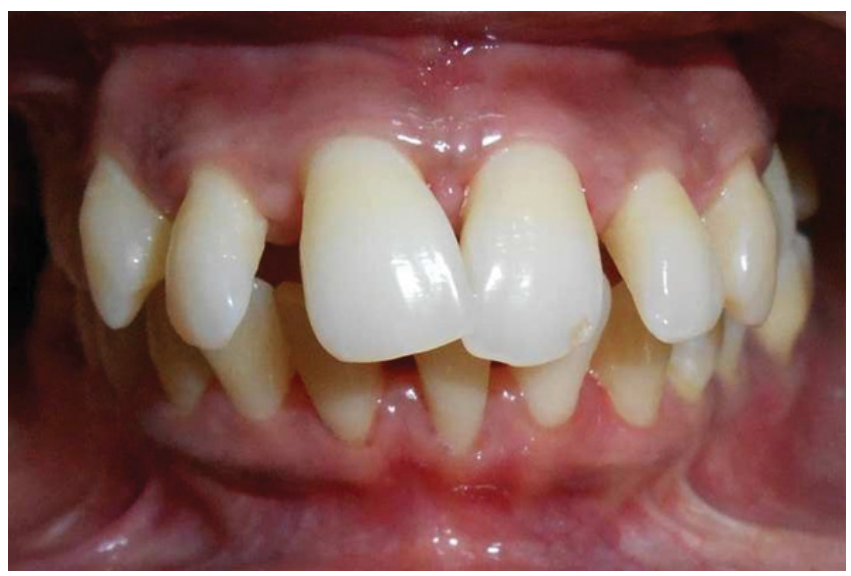

Figure 8: 6 months post-operative view of case 3.

for generalized gingival swelling in gums for 6 months. The patient gave a history of the same condition 2 years back, which was treated. Intraoral examination revealed the patient was a mouth breather with an anterior open bite and poorly maintained oral hygiene (Figure 9). Full mouth oral prophylaxis was carried with root planning (Figure 10) proceeded by gingivectomy with electrosurgery in the maxillary front sextant (Figure 11) and in the mandibular front sextant bone loss was

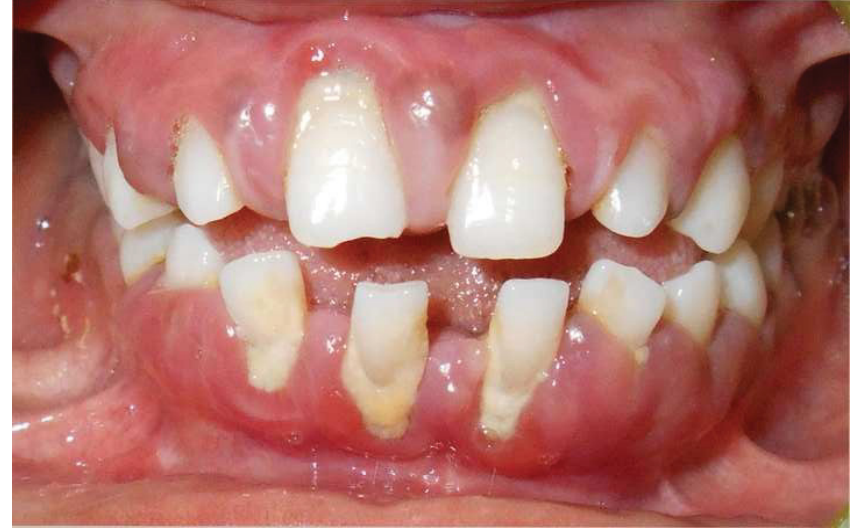

Figure 9: Pre-scaling view of Case 4

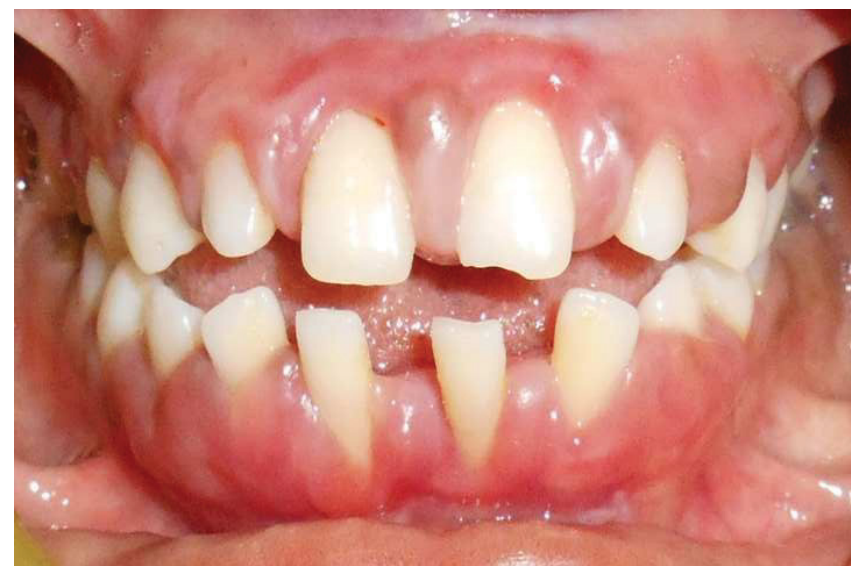

Figure 10: Post-scaling view of case 4

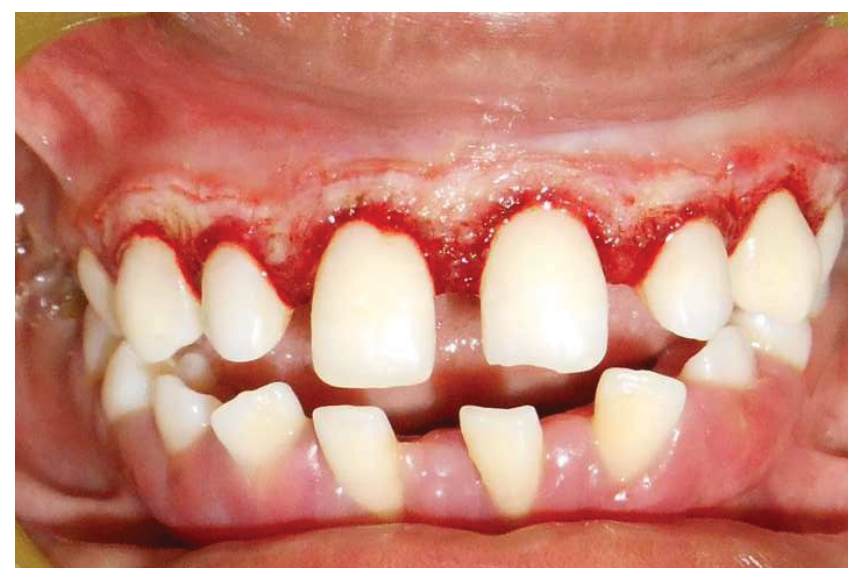

Figure 11: Electrosurgery in upper anteriors of case 4.

evident in the intraoral periapical radiograph, hence modified Widman flap was performed to improve the aesthetic look. After measuring the pocket with a pocket marker, internal bevel incision was placed, debridement was done and the periodontal dressing was placed (Figure 


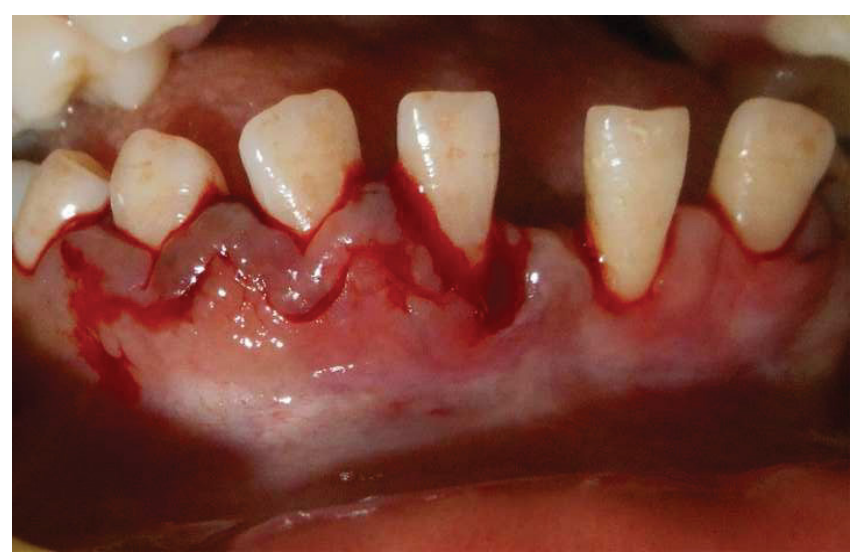

Figure 12: Internal bevel gingivectomy in lower anteriors of case 4 .

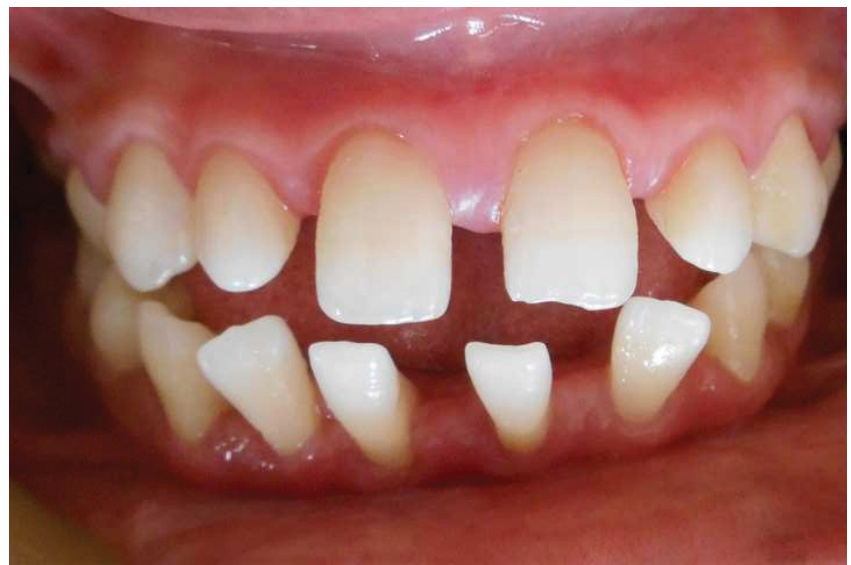

Figure 13: 6 months post-operative view of case 4

12). The recall was done every month which included complete oral care with supra and subgingival scaling, followed by orthodontic therapy to correct the anterior open bite (Figure 13).

\section{Discussion and Conclusion}

According to Seymour, et al. [8] multiplex factors affect the link between gingival tissues and the drugs, which include age, genetics, pharmacokinetics, hormonal, histologic changes inflammatory developments, drug effect on growth factors.
In case 1 , Phenytoin-induced drug enlargement was managed by substituting with sodium valproate and a subsequent change in gingival tissue was evident within a week with scaling and root planing. In case 2 (combined enlargement) there was no drug substitution; periodontal treatment alone yielded a satisfactory clinical response. There is every chance that gingival enlargement can re-establish if the related drug is continued with the presence of other jeopardizing factors. Hence, the patient should be made aware of such recurrences [9]. Thus the patient should maintain good oral hygiene practices, to refrain gingival enlargement related to these drugs.

In case 3, inflammatory gingival enlargement was effectively managed with good oral prophylaxis followed by any persistent enlargement and pockets with open flap debridement. In case 4, inflammatory gingival enlargement combined with mouth breathing was managed with electrosurgery in upper anterior sextant and internal bevel gingivectomy in lower anterior sextant for the preservation of aesthetics. All the cases were then monitored with proper oral hygiene reinforcement.

Maintenance (supportive periodontal therapy) is a must to maintain good gingival condition to prevent the re-establishment of gingival enlargement. Thus the effective management of gingival enlargement needs a thorough diagnosis and then its disparate management. Further, in-depth studies are needed to establish the link between drugs and gingival enlargement for prevention and improved treatment.

\section{References}

1. Brunet L, Miranda J, Farre M, Berini L, Mendieta C (1996) Gingival enlargemen induced by drugs. Drug Saf 15: 219-231.

2. Clocheret K, Dekeyser C, Carels C, Willems G (2003) Idiopathic gingival hyperplasia and orthodontic treatment: A case report. J Orthod 30: 13-19.

3. Rodriguez Y, Baena R, Rizzo S, Fiandrino G, Lupi S, et al. (2011) Mandibula traumatic peripheral osteoma: A case report. Oral Surg Oral Med Oral Pathol Oral Radiol Endod 112: 44-48.

4. Rees TD, Levine RA (1995) Systemic drugs as a risk factor for periodontal disease initiation and progression. Compendium 16: 20,22,26.

5. Jorgensen MG (1997) Prevalence of amlodipine-related gingival hyperplasia J Periodontol 68: 676-678.

6. Nery EB, Edson RG, Lee KK, Pruthi VK, Watson J (1995) Prevalence of nifedipine-induced gingival hyperplasia. J Periodontol 66: 572-578.

7. Savage NW, Daly CG (2010) Gingival enlargements and localized gingival overgrowths. Aust Dent J 55: 55-60.

8. Seymour RA, Thomason JM, Ellis JS (1996) The pathogenesis of drug-induced gingival overgrowth. J Clin Periodontol 23: 165-175.

9. Mavrogiannis M, Ellis JS, Thomason JM, Seymour RA (2006) The management of drug-induced gingival overgrowth. J Clin Periodontol 33: 434-439. 